RESEARCH ARTICLE

\title{
Education Management Information System - Three-Tier Web Application Prototype for Education Workflow
}

\author{
Sridevy S* \\ *Department of Physical Sciences \& Information Technology, Tamil Nadu Agricultural University, Coimbatore-641 003
}

\begin{abstract}
Agriculture education in India is unique with a flexible course credit system. The workflow behind this unique education system needs customized education management information software for educational planning and management with a reduced process time in education workflow. This paper put forth a prototype of the Education Management Information System (EMIS) developed for Forest College and Research Institute (FCRI), Tamil Nadu Agricultural University, Mettupalayam. Three-tier architecture is used for FCRI-EMIS to be an effective distributed client/server system. The development is carried out in an open-source development platform. FCRI-EMIS is developed with four modules namely: College Management Information System, Degree Management Information System, Syllabus Management Information System and Student Management Information System to access, generate a report and analyze the identified entities. The developed prototype is executed and found an effective tool for decision making towards education planning and management.
\end{abstract}

Received : $17^{\text {th }}$ August, 2020

Revised : $08^{\text {th }}$ September, 2020

Accepted : $23^{\text {rd }}$ September, 2020

Keywords: Agriculture education; Education workflow; Educational planning and management; Three-tier architecture; Decision making.

\section{INTRODUCTION}

Agricultural education in India develops human resource capabilities to meet the future challenges of the agricultural industry. The ever-increasing demand for food increases the complexity of empowering human resources (Tamboli et al., 2013). Hence, the agricultural education system in India is dynamically updated to strengthen the agricultural education. Decision making and planning process plays a vital role in educational planning and management to strengthen the education system (Hollands and Escueta, 2020). The decision-making process is data driven (Husein, 2014). Education workflow data that are collected manually are recorded either in ledgers or in excel sheet by the staff, which are (i) prone to errors (ii) lack of security (iii) duplication of data (iv) data inconsistency (v) lack of backups and (vi) time consuming process (Kelly and Casey, 2015). Providing consistent data is required for making right decision making. The data pertained to education workflow has to be collected, organized, stored, analysed and made accessible to all the functionaries involved in the education system (Vijaya et al., 2016). Education institutions aim to provide advantage for the students through the education planning and management by analyzing the data in hand. Education institutions need EMIS to propel the progress to align academic processes and deliver better student experience (Balram, 2018). As per UNESCO (United Nations Educational, Scientific and Cultural Organization) Digital Library, EMIS is a system for organizing information base in a systematic way for the management of educational development (Tegegn, 2003). Prewritten EMIS software such as Open EMIS (Open Education Management Information System) launched by UNESCO are available either as paid or free software but again need to be customised by and for the educational institutes to meet specific requirement of the institute (Kurt, 2001). Education institutes having the constituent colleges spread across the state need web based EMIS to access the core elements of EMIS anywhere at any time. Hence, EMIS requires effective distributed client/server design (Duan and Zhang, 2007 \& Dissanayake and Dias, 2017).

This work is carried out to develop the prototype of web based EMIS for Forest College and Research Institute (FCRI) of Tamil Nadu Agricultural University, Coimbatore with objectives:

- To develop a prototype of management information system that collects, stores, processes, analyses and disseminates FCRI education workflow information for educational planning and management 
- To develop centralized integrated repository of education management information and

- To reduce the process time in education workflow.

\section{MATERIAL AND METHODS}

The prototype developed to provide error free, consistent, non-redundant and updated data anywhere at any time; centralized integrated repository of education management information; to analyse and report demanded information by the decision makers and planners. Learning management System (LMS) is an application software to enhance the learning process. LMS facilitates the teachers to create and deliver eLearning content. The proposed development is not used to deliver course content for e-learning as Learning Management System (LMS) (Steve, 2017).

\section{Pre-Design Phase}

In the pre-design phase Software Requirement Specification (SRS) document is developed describing functional and non-functional requirements of the proposed prototype (Ashima and Gaurav, 2019). Forest College and Research Institute Education Management Information System is a Web App that can be accessed by any computer/mobile with internet access regardless of what operating system the end user device has. Software suitability is carried out to address the objectives and the following open source software are chosen, downloaded and installed with Model-View-Controller Architecture Pattern (Rinci et al., 2017):

- Front end: PHP (Robin, 2015)

- Back end: MySql (Robin, 2015)

- Server: WAMP (Robin, 2015)

- Framework: Codelgniter (Rohit and Yogeshchandra, 2018)

- Editor: Sublime Text Editor (Ken, 2013)

- Responsive cross browser rendering: Bootstrap Framework (Befekadu, 2017 \& Priyanka, 2017)

- Architecture: 3-tier (Figure 1) (Dong et al., 2008)

\section{Requirement Engineering}

Requirement engineering for web app development is similar to the system analysis of Software Development Life Cycle (SDLC) (José and Nora, 2004). System analysis is carried out to identify and document the requirements for FCRIEMIS to support organizational activities (Steven and Glenn, 2005). Preliminary analysis revealed development of education management system is in need to have centralised education information repository and to ensure information availability even if the course teacher or coordinator gets transferred. An extensive system study is carried out to identify the entities; add attributes for entities and give meaningful attribute names; identify the relationship between entities; and to acquire full knowledge of problems and errors (Orawit and Khanithep, 2016)

Logical Design is carried out to list and figure out the relationship between entities. The identified entities and their attributes are:

\section{ENTITY: COLLEGE}

\section{Attributes of College}

College name, objective, vision, address, degree programmes offered, contact details: mailed, phone, mobile, and fax, list of departments etc.

\section{ENTITY: DEPARTMENT}

\section{Attributes of Department}

Department name, Head of the Department, vision, action plan of the department, courses offered by the department, total credit load of the department offered to UG, PG \& Ph.D., List of the Faculties, UG coordinator, PG coordinator, research coordinator, research schemes: PIs, Co-PIs, funding agency, budget, duration, status, contact details etc.

\section{ENTITY: DEGREE}

\section{Attributes of Degree}

Name of the degree programmes offered for UG, PG and Ph.D., Pattern (Semester/Trimester) Number of students permitted to admit quota wise (ICAR, NRI, Industrial), Duration, Fees details for UG, PG and Ph.D. quota wise (ICAR, Industrial, NRI), Penalty for late fee payment etc.

\section{ENTITY: SYLLABUS}

\section{Attributes of Syllabus}

Name of the syllabus for UG, PG, and Ph.D., period in which the syllabus offered, number of years offered, structure of the syllabus, Courses offered semester wise, Flaws in the syllabus, Feedback on the syllabus from administrators, staffs, experts and students, Experiential Learning, RAWE, Project, Tour, Optional courses, MOOC courses, Certification courses etc.

\section{ENTITY: STAFF}

\section{Attributes of Staff}

UPF/CPF number, Name of the staff, qualification, designation, gender, date of birth, photo, experience in years, specialization, courses handled, publications, awards, UG project guide, PG/Ph.D. guided, additional role, university sub projects, externally funded projects, venture 
capital scheme, training/workshop/ conference organised and attended, extension activities involved, e-content developed, teaching aids used, practical manuals prepared, text books/ books published, question banks prepared, tour programme executed, experiential learning course offered, year coordinator, academic counsilor, RAWE programme coordinated, warden/deputy warden, student club/symposium organised, participation in student related activities, education cell activities, contact details etc.

\section{ENTITY: STUDENT}

\section{Attributes of Student}

ID number, name, degree programme, year of admission, gender, parent/guardian name, address, community, physically challenged, mother tongue, any other languages known other than English, medium of school education, rural/urban, identification mark, admission quota, first graduate, percentage of marks scored in S.S.L.C. and HSc, courses studied in HSc, extracurricular activities, sports, awards received if any, e-mail ID, mobile number, parents' mobile number, day scholar/ Hostelite, mess bill payment, semester fee payment, Semester number, courses registered, courses not cleared, marks scored in individual subjects, reregistration details, course completion details, OGPA, grade in the each course, performance analysis, conduct details, etc.

\section{Entity Relationship Diagram (ERD)}

Entity Relationship Diagram (ERD) is a technique used to model the data from the field of system analysis (Malcolm and John, 2010). In this work ERD (Figure 2) is drawn to: define terms related to entity relationship modelling; provide a preview of tables should connect, what fields are going to be on each table; describe entities, attributes, relationships; build databases quickly; act as blueprint for implementing data in application; gain a better understanding of the information to be contained in the database; communicate with the logical structure of the database to users and bring out primary keys and foreign keys.

\section{Education management information system proposed is designed with the following modules:}

- College Management Information System - is a centralised repository of information about the various departments, courses offered by the department, staff of the institute.

- Degree Management Information Systemis an organised collection of information for accessing and reporting degree programmes offered

- Syllabus Management Information System - is providing a platform to analyse the syllabus along with the detailed information of the syllabus

- Student Management Information System - is a repository of individual students' information for custom reports demanded by the end users and analysing the student performance reports to support decision making

\section{RESULTS AND DISCUSSION}

Prototype of the education management system for the forest college and research institute is developed with the following components.

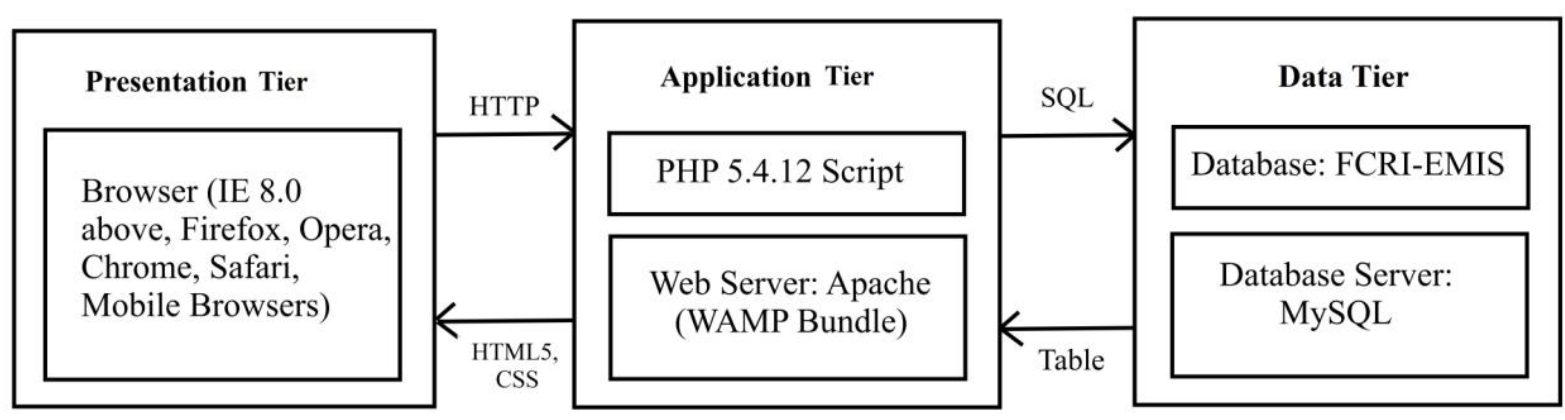

Figure 1. Three Tier Architecture underlying FCRI-EMIS

\section{Opening Screen and Login Form}

Opening screen of the system comprises of buttons to open up login form, sign up form, introduction about the system, links for college management information system, degree management information system, syllabus management information system and student management information system (Figure 3 \& Figure 4). The sign-up form allows the end users with email ID in TNAU domain for administrator and teachers and ID numbers for the students. Three different rolls are defined for the users as follows:

$107|7-9| 324$ 


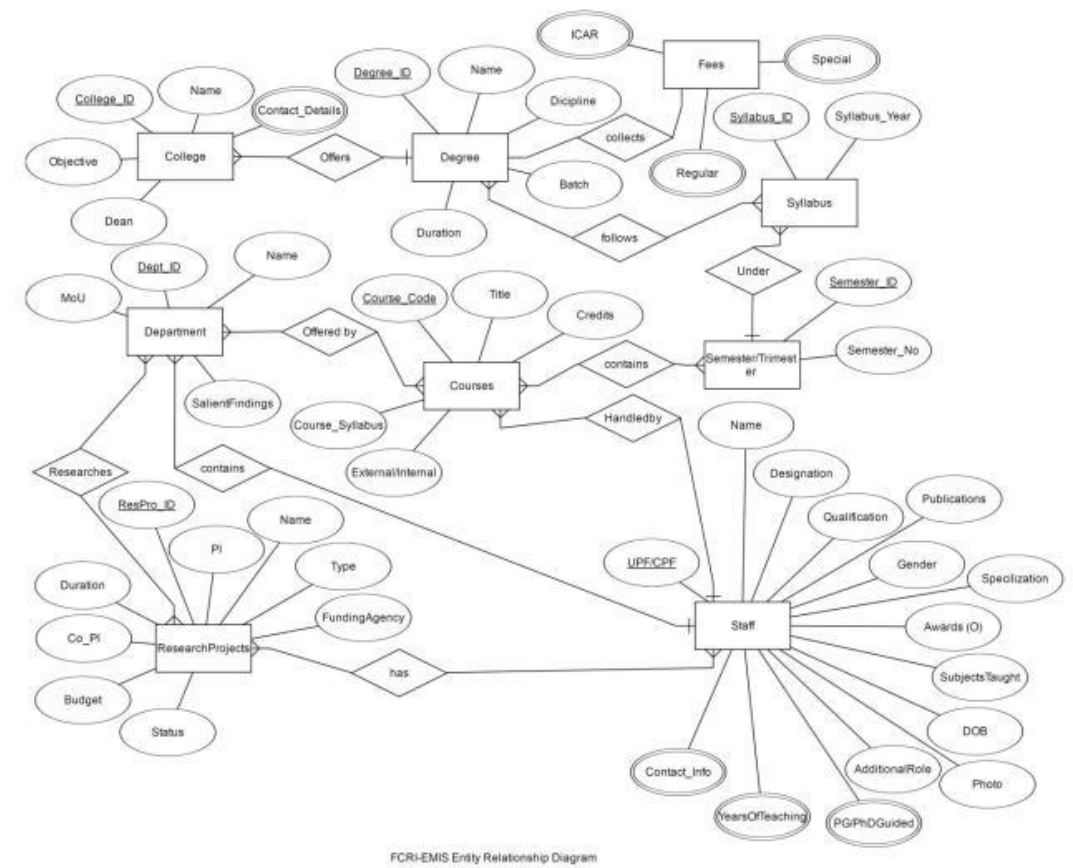

Figure 2. Entity Relationship Diagram

- Administrator roll is defined with all permissions.

- Teachers are the privileged users to update and submit the information.
- Students are permitted to view the required information.

\section{College Management Information System}

College management information system is a
Forest College and Research Institute

Tamil Nadu Agricultural University

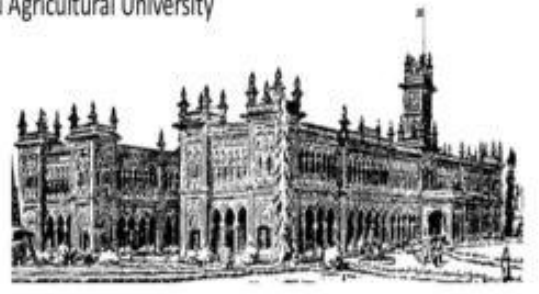

\section{FCRI-EMIS}

Forest College and Research Institute Education Management Information System collects, stores processes, analyzes and desimenates information for educational planning and management. FCRI-EMIS is a centralized integrated repository of education education work flow.

Analyze

\section{College Management Information System}

CMIS is a repository of colleges and DMIS on querying provides research institutes of Tamil Nadu details of degree programmes Agricultural University.

More Info offered by the institute.

Degree Management Syllabus Management
Information System Information System

SyMIS is an intelligent system to extract and analyze to assist decision making process.

More Info
Student Management Information System

StuMIS is a transaction processing management system which provides demand based processed students' information. More Info

Figure 3. Opening Screen 
centralised repository of information about the various departments, courses offered by the departments and staffs of the individual College and
Research Institutes of Tamil Nadu Agricultural University (Figure 5 \& Figure 6). User is allowed to choose the college and research institute from the

\section{Enter the login details}

\begin{tabular}{l} 
UserName \\
Password: \\
\hline Submit
\end{tabular}

Figure 4. Login Form

list box. Information such as college name, objective, vision, address, degree programmes offered, contact details: mailid, phone, mobile, and fax, along with location are displayed.

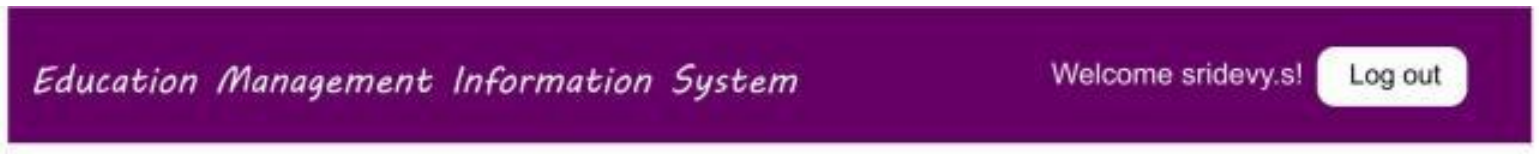

Modules

College Management Information System

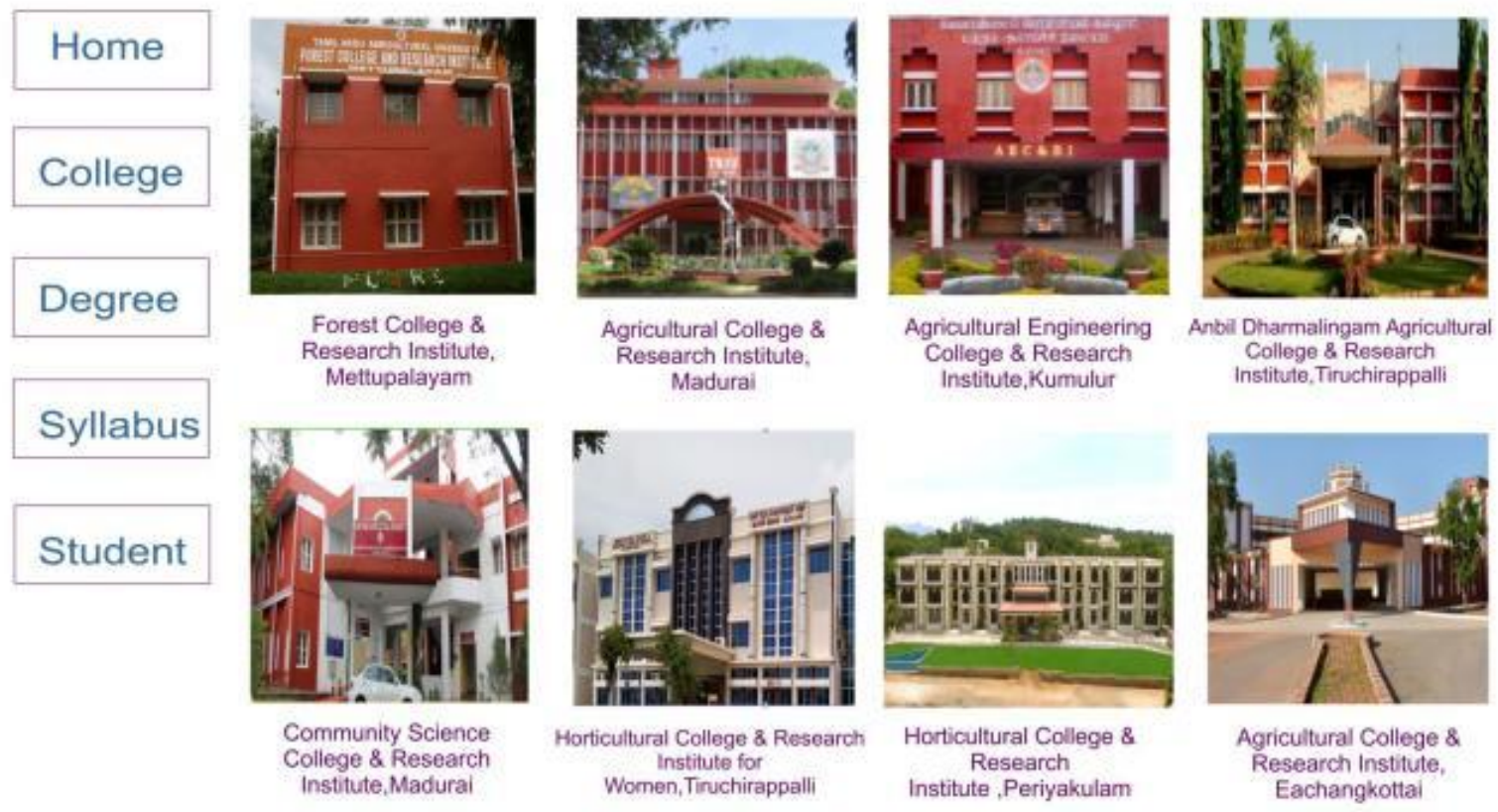

Figure 5. Tile of Constituent Colleges of Tamil Nadu Agricultural University

\section{Degree Management Information System}

Degree Program Management Information System is an organised collection of information for accessing and reporting degree programmes offered and lists names of the degree programmes offered for UG, PG and Ph.D. (Fig. 7). Upon choosing the degree programme introduction about the degree programme, starting year of degree programme, Pattern (Semester/Trimester), Number of students 


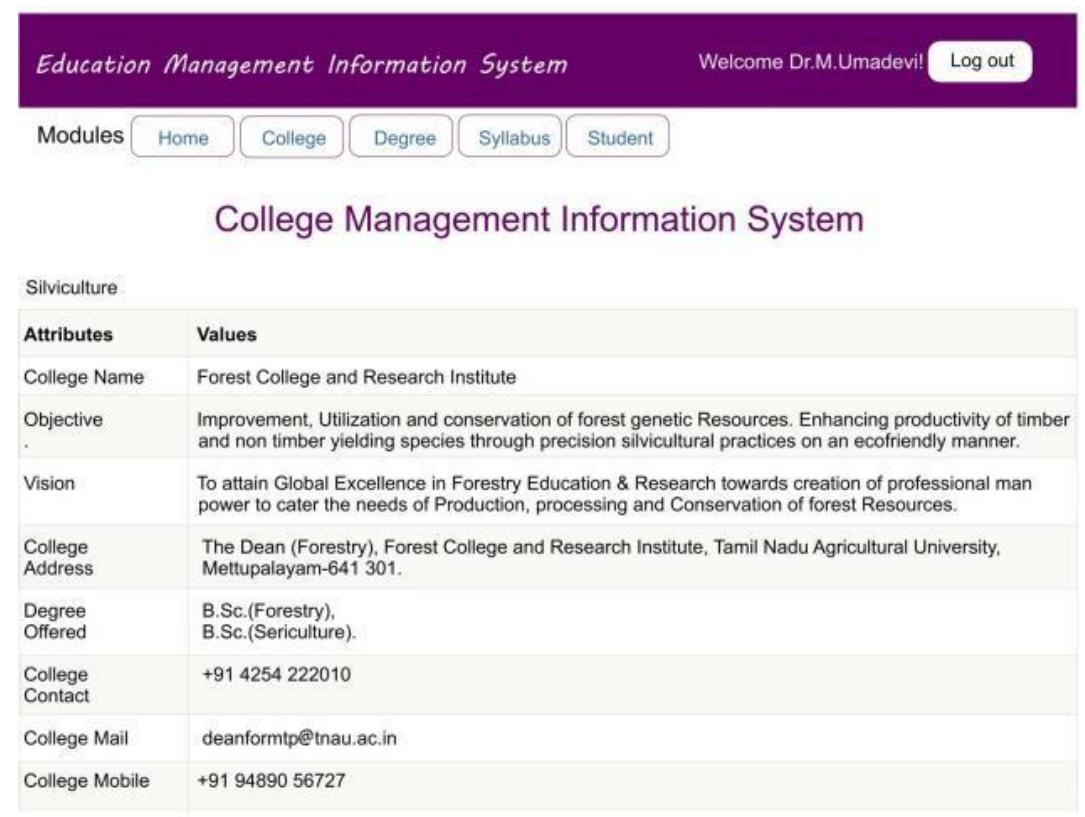

Figure 6. Details of FC\&RI, TNAU, Mettupalayam

admitted under regular, ICAR, NRI and Industrial quota, Duration, Fee details for UG, PG and Ph.D.,
Penalty for late fee payment, admission procedure, etc. are displayed (Figure 7).

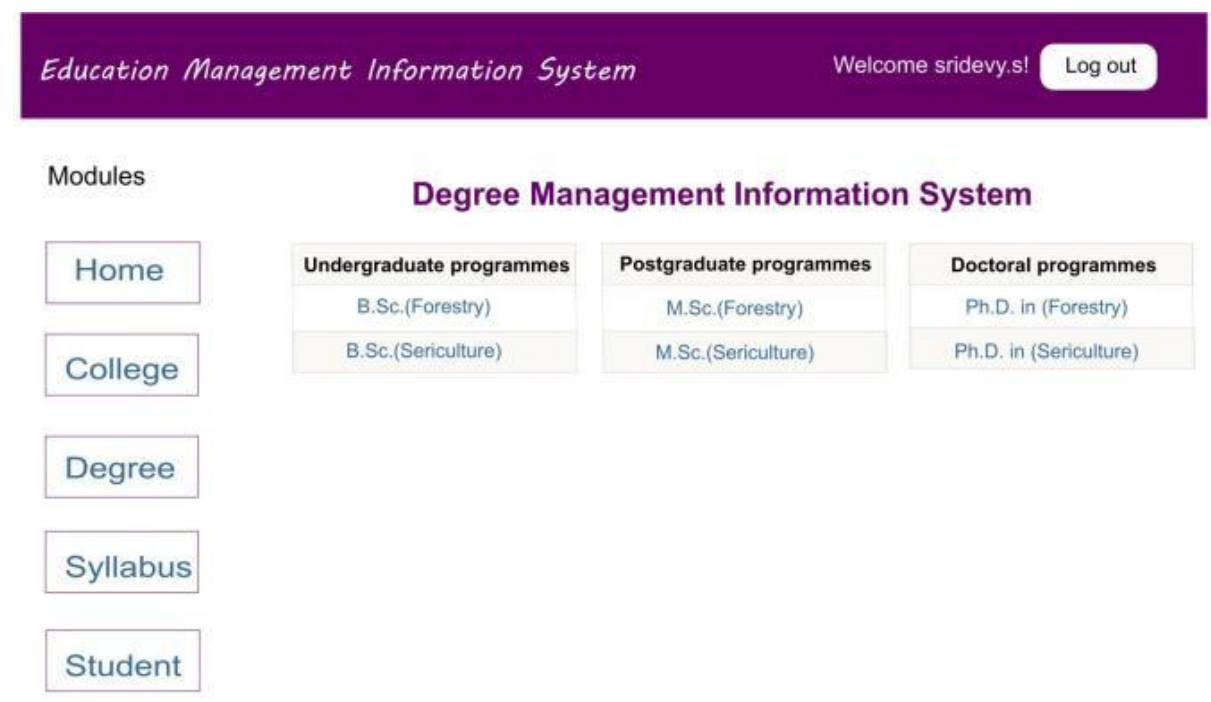

DS. Sridevy. Assistant Professor(Computer Science), Dept. of Tree breeding, Forest College and Research Institute, Tamil Nadu Agricultural University,Mettupalayam.

Figure 7. Degree Programmes Offered by FC\&RI, TNAU, Mettupalayam

\section{Syllabus Management Information System}

Syllabus management information system is providing a platform to analyse the syllabus along with the detailed information of the syllabus and enlists the syllabus for UG, PG, and Ph.D., period in which the syllabus offered, number of years offered, structure of the syllabus, Courses offered semester wise, Weaknesses in the syllabus, Feedbacks on the syllabus from administrators, staffs, experts and students etc. (Figures $8 \& 9$ ). 


\section{Student Management Information System}

Student information system is repository ID number, name, degree programme, year of admission, gender, parent/guardian name, address, community, physically challenged, mother tongue, any other languages known other than English, medium of school education, rural/urban, identification mark, admission quota, first graduate, percentage of marks scored in S.S.L.C. and H.Sc., courses studied in H.Sc, extracurricular activities,

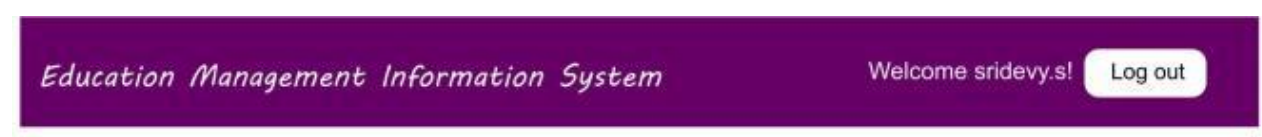

Modules

\begin{tabular}{|l|}
\hline Home \\
\hline College \\
\hline Degree \\
\hline Syllabus \\
\hline \\
\hline Student \\
\hline
\end{tabular}

Syllabus Management Information System

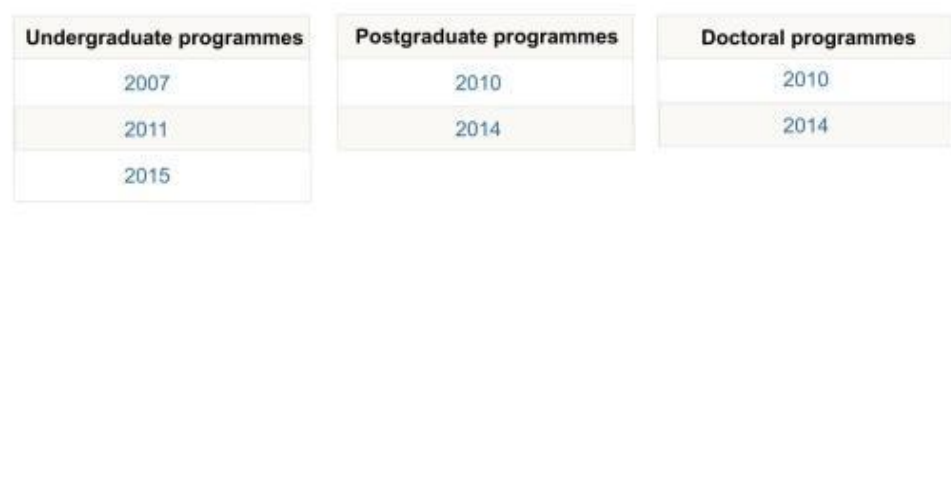

(1) S. Sridevy. Assistant Professor(Computer Science), Dept. of Tree breeding, Forest College and Research Institute, Tamii Nadu Agricultural University, Mettupalayam.

Figure 8. Syllabi of Various Degree Programmes

sports, awards received if any, e-mail id, mobile number, parents' mobile number, day scholar/ hosteler, mess bill payment, semester fee payment, semester number, courses registered, courses not cleared, marks scored in individual subjects, re-registration details, course completion details,

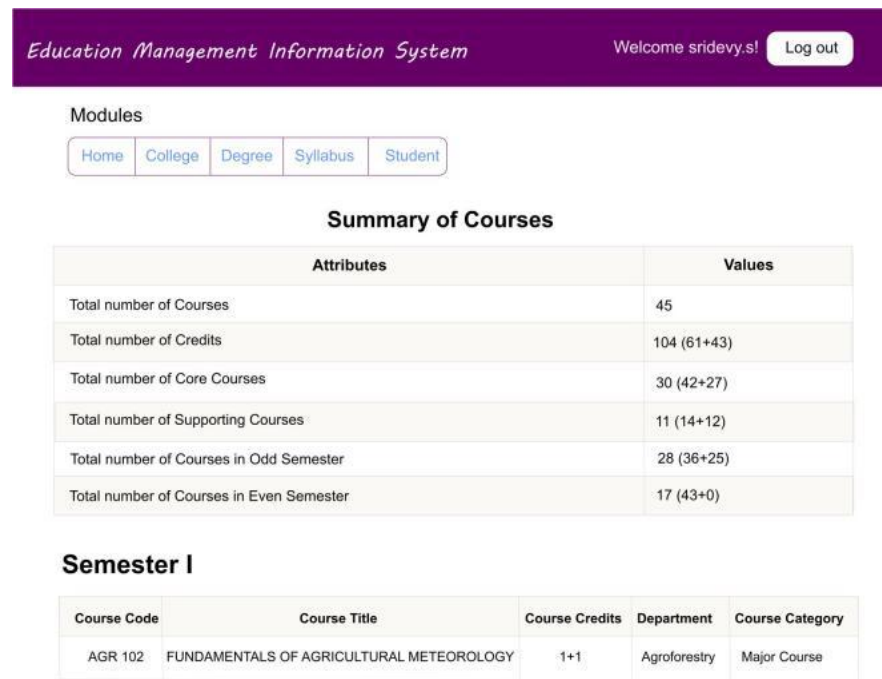

Figure 9. Summary of Courses

OGPA, grade in the each course, performance analysis, conduct details, etc. (Figure 10).

\section{Testing}

In the testing phase the errors were identified and corrected. For example, mysql_fetch_array() error in the following code results a warning message shown in Figure 11.

\$query = ‘SELECT d.degree_name, d.established_ year, c.colg_name FROM degree_master53 d, 


\section{SQL result}

\section{Host: localhost}

Database: $\mathrm{cmis}$

Generated Time: November 03,2020 at 02:20 PM

Generated by: phpMyAdmin 4.0.4 / MySQL 5.6.12-log

SQL query: SELECT * FROM 'batch_master' LIMIT 0,12;

Rows: 12

\begin{tabular}{|l|l|l|l|l|l|l|l|}
\hline batch_id & batch_name & degree_id & discipline_id & syllabus_id & start_date & end_date & $\begin{array}{l}\text { no_students_ } \\
\text { admitted }\end{array}$ \\
\hline 1 & 2011 & 1 & 1 & 2 & 2011 & 2015 & 34 \\
\hline 2 & 2012 & 1 & 1 & 2 & 2012 & 2016 & 49 \\
\hline 3 & 2013 & 1 & 1 & 2 & 2013 & 2017 & 43 \\
\hline 4 & 2014 & 1 & 1 & 2 & 2014 & 2018 & 38 \\
\hline 5 & 2015 & 1 & 1 & 3 & 2015 & 2019 & 47 \\
\hline 6 & 2016 & 1 & 1 & 3 & 2016 & 2020 & 53 \\
\hline 7 & 2011 & 2 & 1 & 2 & 2011 & 2015 & 27 \\
\hline 8 & 2012 & 2 & 1 & 2 & 2012 & 2016 & 29 \\
\hline 9 & 2013 & 2 & 1 & 2 & 2013 & 2017 & 29 \\
\hline 10 & 2014 & 2 & 1 & 2 & 2014 & 2018 & 24 \\
\hline 11 & 2015 & 2 & 1 & 3 & 2015 & 2019 & 22 \\
\hline 12 & 2016 & 2 & 1 & 3 & 2016 & 2020 & 27 \\
\hline
\end{tabular}

Figure 10. Section of Query Result on Students' Strength Admitted

college_master $c$ where c.colg_id $=$ d.college_id and d.degree_id='.\$deg_id.';';

Parameter name in the above code is corrected as given below to display attributes of degree (Figure 12).

\$query = ‘SELECT d.degree_name, d.established_ year, c.colg_name FROM degree_master d, college_ master c where c.colg_id = d.college_id and d.degree_id='.\$deg_id.';';

Error occurred due to undefined variables as shown in Figure 13 are corrected to display the correct results (Figure 9).

\section{Education Management Information System}

Modules Home College Degree Syllabus Student

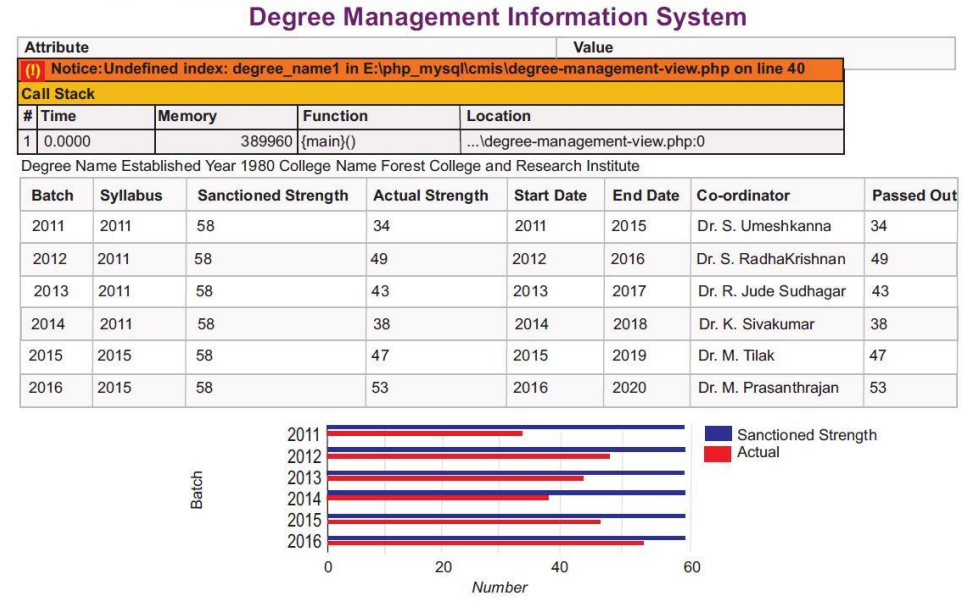

(c) s.Sridevy, Assistant Professor (Computer Science), Dept. of Tree Breeding, Forest College and Research Institute, Tamil Nadu Agricultural University, Mettupalayam

Figure 11. mysql_fetch_array() error

\section{Data Generation and Impact Use}

The study reveals the need for strengthening of EMIS at all levels especially at academic level by providing adequate resources in terms of human, financial and equipment and increase in data coverage through legal and administrative mandates for the colleges. Other education data sources should be integrated with EMIS databases at all levels to complement and support annual academic data. There should be conformity and compatibility, through standards, in data capturing $107|7-9| 329$ 
Modules Home College Degree Syllabus Student

Degree Management Information System

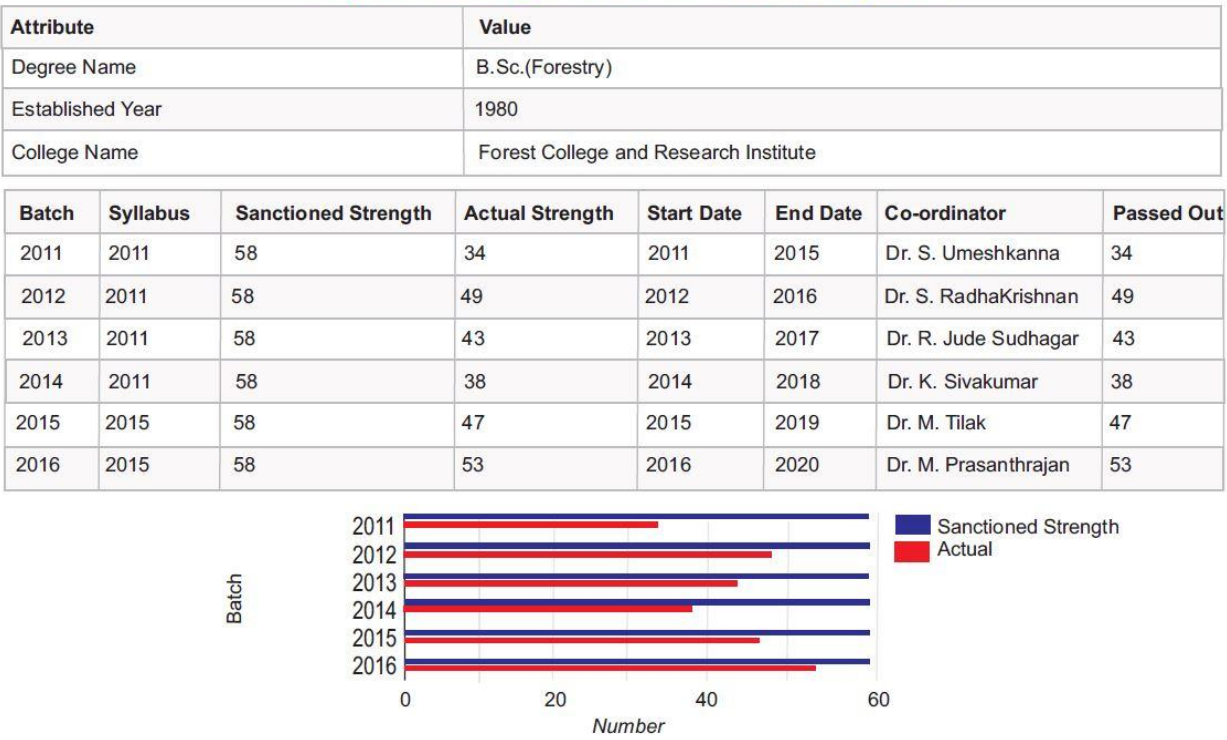

(c) S.Sridevy, Assistant Professor (Computer Science), Dept. of Tree Breeding, Forest College and Research Institute,Tamil Nadu Agricultural University, Mettupalayam

Figure 12. Result displayed after correcting mysql_fetch_array() error

and coding, database structure, data entry and storage software, and data verification procedures. EMIS should focus on collecting qualitative data about academic process and students' outcomes, as well as education finance data. The data reporting format should be made user friendly and it should contain analytical text and education indicators. The EMIS should evolve reporting and information dissemination strategy to provide information to all stakeholders in a suitable format.

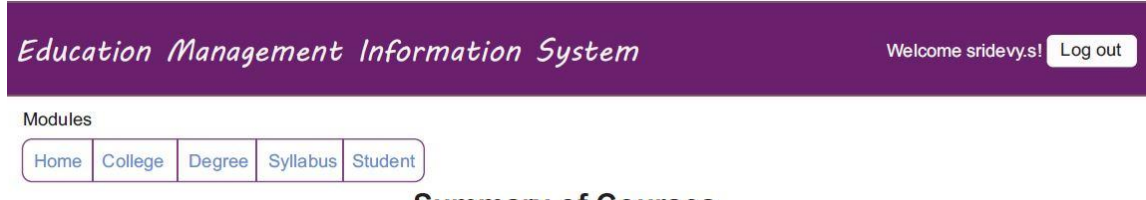

Summary of Courses

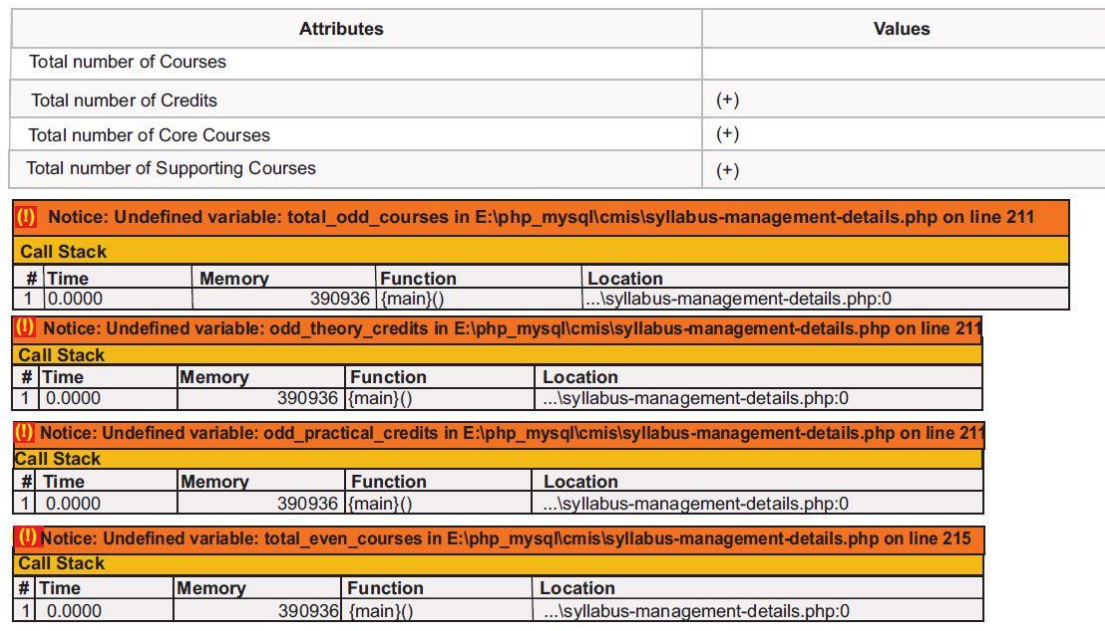

Figure 13. Undefined variable error 
On the basis of data gap identified by decision makers at various levels, the provincial EMIS should collect data relating to annual examination results and students assessment, students drop-out, budget allocation and expenditure, college wise receipt of funds and utilization, additional facilities required in laboratory, students' attendance, capacity building needs of faculties, supervision by Dean, development schemes additional classrooms, and science laboratories, complete profile of teaching and non-teaching staff and number of students who need financial assistance.

\section{CONCLUSION}

EMIS data may be used at all administrative levels in various types of decisions such as situation analysis, target setting, budget preparation, formulation and appraisal of projects, textbooks purchase, construction of classrooms, staring of new programs, and provision of basic facilities. The majority of data users at all administrative levels were satisfied with the quality of EMIS data, however, level of satisfaction with quality of data varied across administrative levels. The data gaps identified by users included enrolment by age, failure, dropouts, students' performance, faculty performance and financial data.

In this paper, a prototype for education management information system has been developed. The developed prototype will serve as an alternative to the conventional system to manage the education workflow. The main intention of this prototype is to develop software which provides assistance in decision making for educational planning and manage it more effectively. EMIS ensures persistent data availability, integrity and confidentiality which plays a vital role in enhancing the quality of education system of an organization. This system allows Academic leadership to easily identify gaps and track the installation, usage and maintenance of all college facilities and infrastructure in the institute.

In short, EMIS is an excellent example of how IT has transformed the management of education despite many difficulties to success.

\section{REFERENCES}

Ashima Rani and Gaurav Aggarwal. 2019. Algorithm for Automatic Detection of Ambiguities from Software Requirements. International Journal of Innovative Technology and Exploring Engineering, 8(9S): 878-882.

Balram Korde. Role of Management Information System (MIS) in Education Sector.2018. [Internet]. Availble from: https://www.iitms.co.in/blog/role-ofmanagement-information-system-in-education.html

Befekadu Mezgebu Temere. 2017. Responsive Web Application Using Bootstrap and Foundation -
Comparing Bootstrap and Foundation Frontend Frameworks. Helsinki Metropolia University of Applied Sciences Bachelor of Engineering Programme Information Technology Thesis.

Dissanayake, N.R. and G.K.A. Dias. 2017. Web-based Applications: Extending the General Perspective of the Service of Web. 10th International Research Conference of KDU (KDU-IRC 2017) on Changing Dynamics in the Global Environment: Challenges and Opportunities, Rathmalana, Sri Lanka, University of Colombo School of Computing, Colombo 7, Sri Lanka.

Dong-Yup Lee, Rajib Saha, Faraaz Noor KhanYusufi,Wonjun Park and Iftekhar A. Karimi.2008. Web-based applications for building, managing and analysing kinetic models of biological systems. Briefings in Bioinformatics, 10(1): 65-74.

Duan, R. and M. Zhang. 2007. Design of Web-based Management Information System for Academic Degree \& Graduate Education. In: Wang W., Li Y., Duan Z., Yan L., Li H., Yang X. (eds) Integration and Innovation Orient to E-Society Volume 2. IFIP International Federation for Information Processing, vol 252. Springer, Boston, MA.

Hollands, F. and M. Escueta. 2020. How research informs educational technology decision-making in higher education: the role of external research versus internal research. Education Tech Research De, 68: 163-180.

Husein Abdul Hamid.2014. What Matters Most for Education Management Information Systems:A Framework Paper. Saber - Systems Approach for Better Education Results Education Management Information Systems. World Bank Group.

José Escalona, M. and Nora Koch. 2004. Requirements Engineering for Web Applications - A Comparative Study. J. Web. Eng.,, 2(3): 193-212.

Kelly Rainer, R. and Casey G. Cegielski. 2015. Introduction to Information systems. John Wiley \& Sons Inc.

Ken Kinder. 2013. Sublime Text: One Editor to Rule Them All? Linux Journal [Internet]. Available from: https://www.linuxjournal.com/content/sublimetext-one-editor-rule-them-all.

Kurt Moses. 2001. Education management Information Systems (EMIS): Available Software and Guidelines for Selection. [Internet]. Available from: https:// www.openemis.org/

Malcolm Brady and John Loonam. 2010. Exploring the use of entity-relationship diagramming as a technique to support grounded theory inquiry. Qualitative Research in Organizations and Management 5(3): 224-237.

Orawit Thinnukool and Khanithep Pitupumnak. 2016. Shedding Light on the National Identity of Local Music in Northern Thailand: Design and Implementation via Responsive Web Application. Indian Journal of Science and Technology, 9(16): 1-10.

Priyanka Panchal. 2017. Responsive Web Design and Web Development Using Bootstrap Frond-End 
Framework. International Journal of Advance Research in Science and Engineering, 6(7):1-8.

Robin Nixon. 2015.Learning PHP, MySQL \& JavaScript, with jQuery, CSS \& HTML5, 4th Edition. O' Reilly.

Rohit Jahagirdar and Yogeshchandra Puranik. 2018. A Review on Codeigniter. International Journal of Trend in Scientific Research and Development, 2 (4): 1124-1129.

Rinci Kembang Hapsari, Azmuri Wahyu Azinar and Sugiyanto. 2017. Architecture Application Model View Controller (MVC) in Designing Information System of MSME Financial Report. Quest Journals: Journal of Software Engineering and Simulation, 3(7): $36-41$.

Steve Foreman. 2017. The LMS Guidebook: Learning Management Systems Demystified: American Society for Training and Development; Business \& Economics.
Steven Alter and Glenn J. Browne. 2005. A Broad View of Systems Analysis and Design: Implications for Research. Communications of the Association for Information Systems, 15: 981-999

Tamboli, P.M.and Y.L. Nene. 2013. Modernizing higher agricultural education system in India to meet the challenges of 21st century. Asian Agri-History, 17(3): 251-264.

Tegegn Nuresu Wako. 2003. Education Management Information Systems (EMIS) A Guide for Young Managers. UNESDOC Digital Library: Programme and meeting Document. [Internet]. Available from: https://unesdoc.unesco.org/ark:/48223/ pf0000220621.

Vijaya Kumar,T., Deepa, N. and V.Lalitha. 2016. Education Mmnagement Information System:Post Enumeration Survey of U-Disein Telangana State. International and Educational Research Journal, 2(10): 47-52. 